\title{
Risk Influencing Factor Analysis of Urban Express Logistics for Public Safety: A Chinese Perspective
}

\author{
Mingjing Zhao $\mathbb{D}^{1},{ }^{1}$ Shouwen Ji $\left(\mathbb{D},{ }^{1}\right.$ Qianru Zhao, ${ }^{1,2}$ Cheng Chen, ${ }^{3}$ and Zhen-Lin Wei ${ }^{1}$ \\ ${ }^{1}$ School of Traffic and Transportation, Beijing Jiaotong University, Beijing 100044, China \\ ${ }^{2}$ Beijing Jiaotong University Haibin College, Cangzhou, Hebei 061199, China \\ ${ }^{3}$ School of Mechanical-Electronic and Vehicle Engineering, Beijing University of Civil Engineering and Architecture, \\ Beijing 100044, China \\ Correspondence should be addressed to Shouwen Ji; shwji@bjtu.edu.cn
}

Received 10 December 2019; Revised 16 April 2020; Accepted 5 May 2020; Published 17 June 2020

Academic Editor: Mosè Gallo

Copyright (c) 2020 Mingjing Zhao et al. This is an open access article distributed under the Creative Commons Attribution License, which permits unrestricted use, distribution, and reproduction in any medium, provided the original work is properly cited.

\begin{abstract}
Due to the uncertainty and complexity of multilinks and multifactors in urban express logistics system, it is very difficult to analyze the risk factors and the correlation among them for urban public security. In this paper, a method combining domain knowledge and data learning is proposed to construct Bayesian network, which can effectively deal with this problem. Based on the literature review and the investigation of transportation companies, this paper summarizes the risk factors to public safety caused by pick up, warehouse storage, transport, and the end distribution in the process of urban express logistics, which are divided into 5 dimensions: management, weather, human, transportation tools and facilities, and goods, including 11 risk factors. In this paper, Interpretative Structural Model is used to construct the initial hierarchical model to describe the complex relationship between factors, and then causal mapping method is used to improve the initial model to transform the structure into the final Bayesian network model. Finally, the sensitivity of one node to other nodes is analyzed based on the incident data. The results show that Bayesian network is effective in improving urban express logistics operation ability and avoiding public safety risks and has a strong generalization ability, which is simple and easy in practical application.
\end{abstract}

\section{Introduction}

Taniguchi et al. [1] defined urban logistics as "in the market economy, considering the urban traffic environment, traffic congestion, and energy consumption, while private enterprises to achieve the overall optimal logistics and transport activities process." Based on the national conditions of China, this paper gives the definition of urban logistics: urban logistics is an activity that takes improving the competitiveness of a city as the core, realizes the optimization of urban logistics and transportation activities through the application of advanced information technology, and tries to reduce the negative impact of logistics activities on urban traffic congestion, traffic environment, and energy consumption. The operation process of urban express logistics involves many links, such as pick up, warehouse storage, transport, and the end distribution, during which the business status is diverse and the risk factors are numerous, which can easily threaten the public security of the city. The risk of urban public security refers to the force majeure and the possibility of objective existence that threaten the basic values, norms, and interests of urban public domain [2]. The control of urban public security risks should prevent risks and potential harm caused by public security incidents from the source of risk factors.

The risks of urban logistics to public security are mainly manifested as vehicle collision and explosion, warehouse fire and explosion, contraband transportation, burglary, and assault by courier. Frequent in recent years, the Chinese express logistics accidents caused a great deal of personnel and property losses. However, there is no unified system of the research on the risk factors affecting the public security of urban express logistics. At present, most of the research studies focus on the single risk of a certain logistics link, such as the hidden danger in the process of transportation $[3,4]$ and fire risk in logistics storage [5] or the internal risk 
analysis of logistics enterprises, such as the risk cost of logistics enterprises [6], logistics outsourcing risk [7], and project logistics risk [8]. There is no systematic study on the risks and hidden dangers of the whole logistics link to public security. The analysis of risk factors is the primary part of accident prevention because it can provide operational information for logistics-related enterprises and management departments. They can focus on the potential risks and take preventive measures.

At present, risk-based research is generally concentrated in the fields of automobile collision, coal mine, transportation of dangerous goods, and aviation. Commonly used risk research methods include BP neural network [9], fuzzy comprehensive evaluation method [10], analytic hierarchy process (AHP) $[11,12]$, and Bayesian network (BN) $[13,14]$, focusing on the evaluation of risk, but lack of risk identification and control research. Other traditional risk research methods are fault tree analysis (FTA) [15], probability theory [16], Swiss cheese model, human factor analysis, and classification system (HFACS) [17]. However, the various influencing factors in these methods are independent. In reality, these factors are often related to each other.

Based on the above problems, this paper adopts the method of literature review and the survey of transportation companies to divide the factors that affect the risk of urban logistics into five dimensions: management, weather, human, transportation tools and facilities, and goods, including 11 influencing factors. The impact factors of urban logistics on public safety risk are analyzed by using Interpretative Structural Model (ISM), and the initial network model is established. Then, the initial model is transformed into BN model by using causal mapping method. The sensitivity of specific nodes to other nodes is obtained, and the relationship between risk factors of urban logistics is identified. It helps managers to enhance the scientific nature of risk management decisions, provides a new basis for improving the operational stability of urban logistics, helps to reduce the occurrence of urban public security incidents, and alleviates the potential loss of risks to society, economy, and environment.

The rest of this paper is organized as follows: Section 2 presents the historical research on risk identification and ISM. Section 3 introduces the basic theory including BN and ISM. Section 4 constructs a Bayesian network model and analyzes the sensitivity of each node. Section 5 discusses the advantages and future development of this study. Section 6 provides our conclusions.

\section{Literature Review}

Most of the previous research studies that analyzed the factors responsible for urban logistics accidents used a statistical method. The researchers primarily limited to the collection, analysis, and interpretation of data from accident reports or accident databases [13]. Ren [5] analyzed in a large number of fire accidents of logistics warehouses reveal four factors that affect the fire risk: warehouse building, commodity, management, and environment. Zhao et al. [13] collected 94 cases of dangerous goods transportation accidents and adopted the expectation maximization algorithm to derive three main risk factors affecting hazardous materials transportation: human factors, transportation vehicles and facilities, and packaging and loading of dangerous goods. Chen and Liu [18] analyzed the data of logistics road transportation accidents and concluded that the main risk factors include personnel factors, vehicle factors, and road factors. They used the Delphi method to make qualitative analysis of the potential accident, effectively helping the security management personnel of logistics enterprises to recognize the causes and potential problems of truck accidents and take precautions in advance.

Although statistical methods can be used to obtain the accident influencing factors, it cannot explain the connection between the different factors and the important role of key factors in accidents. In recent years, $\mathrm{BN}$ has been widely used in economic analysis [19], biological genetic [20], medical diagnosis [21], mechanical engineering [22], civil engineering [23], transportation [24], computer science [25], mining accidents [26], and other fields. BN is also applicable to the field of logistics. Aiming at the limitation that complex logistics service supply chain system is difficult to carry out reliability analysis in the face of a lot of uncertain fuzzy information, Cai and Liu [27] proposed a reliability analysis method of polymorphic system combining Bayesian network and fuzzy set theory. The reliability analysis efficiency of logistics system is improved and theory and data support for logistics enterprises are provided to improve the weak links. Yan and Suo [28] identified and classified the risks of logistics financial business, took the failure of enterprises as the root node, constructed a Bayesian network to measure the risk level of enterprises, and found the most critical risk factors by calculating several important indicators. Zhu and Yang [29] constructed the early warning index system of agricultural products logistics by using Bayesian network, designed the early warning model, and realized the early warning of agricultural products cold chain logistics.

As far as we know, there are few research papers on the application of BN in logistics risk factor analysis, such as Li et al. [30] based on factor analysis to determine the effect of emergency logistics risk factors. The factors are divided into human factor, equipment factor, materials factor, environment factor, and supervision factor. And the Bayesian network of emergency logistics risk is established. The prior probability and the posterior probability can be used to find the weak links of logistics and realize the rapid positioning of logistics risk. Huang and Qian [31] analyzed the main faults in the process of cold chain transportation using Bayesian network, summarized the influence of different factors on the faults, and provided an effective method for improving the fault analysis and prevention in the process of cold chain transportation.

However, these literature studies only apply BN model to logistics risk and do not discuss how to establish BN model of logistics for public security. This paper proposes a method to construct $\mathrm{BN}$ by means of ISM and causal mapping method and conducts sensitivity analysis on risk factors of urban logistics for public security. The relationship among the factors and the important influencing factors are obtained, and the corresponding methods for accident prevention are put forward. 


\section{Methodology}

3.1. Bayesian Network. Bayesian network is a network combining probabilistic inference and graph. It encodes the probabilistic relationship between the variables of interest. BN can provide a rational and coherent theory under various conditions of uncertainties (e.g., uncertainty in parameters and models or uncertainty in domain knowledge) and complexity that are described by subjective belief or probability [32]. BN has several advantages for data analysis:

(1) It is easy to handle the absence of certain data items.

(2) It can be modeled in terms of causality, so it can be used to gain an understanding of the problem domain and predict the outcome of the intervention.

(3) Since the model has both causal and probabilistic semantics, it is an ideal representation of combining prior knowledge and data (usually in the form of a causal relationship). BN is particularly useful for modeling uncertainty.

Based on the advantages of $\mathrm{BN}$ and its wide application in the field of risk assessment, this paper proposes a hybrid method combining domain knowledge and data learning to construct a $\mathrm{BN}$ and realize the integration of multiple factors and quantification of uncertainty in the network model to assess the public security risks of urban logistics.

$\mathrm{BN}$ is represented by a series of variable nodes and a directed arc representing causality. The conditional probability table (CPTs) is used to determine the quantitative relationship between variables. BN can be represented as $N=(G, P)$, where $N$ represents the network, $G$ represents the graph, and $P$ represents the joint probability of the network. $G$ is a graph, which can be further represented by $(V, E)$, where $V$ represents the set of nodes $\left(x_{1}, x_{2}, x_{3}, \ldots, x_{n}\right)$ and $E$ represents the directed edge of causal relationship between variables. In addition, the calculation method of joint probability equation $P$ on variables is shown in equation (1). The joint probability $P$ is obtained by multiplying the respective local conditional probability distributions:

$$
P\left(X_{1}, X_{2}, \ldots, X_{k}\right)=P\left(X_{k} \mid X_{1}, X_{2}, \ldots, X_{k-1}\right) \cdots P\left(X_{2} \mid X_{1}\right) P\left(X_{1}\right) \text {. }
$$

The construction of BN usually adopts three methods: databased method, knowledge-based method, and the combination of the two methods. The data-based method uses the conditional independence semantics of $\mathrm{BN}$ to generalize the model from the data. The knowledge-based approach utilizes the causal knowledge of domain experts to construct BN. Knowledge-based approaches are particularly useful when domain knowledge is critical and data availability is scarce. The method modeling combining domain knowledge and data is the most commonly used method at present, which not only avoids the dependence on expert domain knowledge, but also avoids the invalid learning when given a small or noisy dataset.

3.2. Interpretative Structural Modeling. Interpretative Structural Modeling (ISM) is developed by Warfield [33] in 1973 when analyzing complex structural problems in socioeconomic systems. The basic idea is to extract the elements of the problem through various creative techniques and use directed graph, matrix, and computer technology to process the information of the elements and their mutual relations. The model is intuitive and instructive and is widely used to recognize and deal with complex system problems. Singh et al. [34] implemented knowledge management in the engineering industry and found the interdependence among the variables. Hu et al. [32] evaluated the seismic liquefaction potential by combining interpretation structure model and BN method and achieved good prediction results. Ravi and Shankar [35] adopted the ISM method to analyze the obstacles in reverse logistics activities and extract the key influencing factors.

The advantages of ISM include the following [25]:

(1) Systematic integration of expert opinions and domain knowledge

(2) Providing enough opportunities for decision modification

(3) For a system with factors between 10 and 15, the amount of calculation is small, which is convenient for practical application

The basic working principle and steps of the method are as follows:

Step 1: determine the factors of the system and relationship table. According to the field knowledge and field research, we can summarize the factors related to the problem. Establish the relationship between various factors according to relevant knowledge in the field.

Step 2: construct a structural self-interaction matrix (SSIM) and calculate the reachability matrix $M$. From the determination of the direct relationship between every two factors, SSIM of each factor is constructed. At this time, the matrix belongs to Boolean matrix and follows the logic operation rules.

For example, there is a system $s$ containing $n$ factors, $s=\left\{S_{i} \mid i=1,2, \ldots, n\right\}$. If factor $S_{i}$ has no influence on factor $S_{j}$, then $a_{i j}$ in the intersection position between the row $S_{i}$ and the column $S_{j}$ is represented as " 0 "; if there is a direct influence, it is represented as " 1 ." The structural self-interaction matrix $A$ is expressed as follows:

$$
\begin{aligned}
& \begin{array}{llll}
S_{1} & S_{2} & \ldots & S_{n}
\end{array} \\
& A=\begin{array}{c}
S_{1} \\
\quad \ldots \\
S_{n}
\end{array}\left[\begin{array}{cccc}
a_{11} & a_{12} & \ldots & a_{1 n} \\
a_{21} & a_{22} & \ldots & a_{2 n} \\
\ldots & \ldots & \ldots & \ldots \\
a_{n 1} & a_{n 2} & \ldots & a_{n n}
\end{array}\right] \\
& a_{i j}=\left\{\begin{array}{l}
1, S_{i} \text { is relative to } S_{j}, \\
0, \text { no relationship between } S_{i} \text { and } S_{j} .
\end{array}\right.
\end{aligned}
$$

By adding the binary relation matrix $A$ and the identity matrix $I$, the connection matrix $N$ can be obtained, and then matrix $M$ can be calculated through Boolean operation. The reachability matrix represents whether there is a connection path from one element to another. 
Step 3: hierarchical decomposition. The reachability matrix is divided into different hierarchical structures. The reachable set $R\left(S_{i}\right)$ represents the factors set reachable by factor $S_{i}$ in the reachable matrix and is defined in the following formula:

$R\left(S_{i}\right)=\left\{S_{j} \mid S_{j} \in S, m_{j i}=1, j=1,2, \ldots, n\right\}, \quad i=1,2, \ldots, n$.

The antecedent set $Q\left(S_{i}\right)$ represents the factors set of reachable factors $S_{i}$ in the reachable matrix and is defined as follows:

$Q\left(S_{i}\right)=\left\{S_{j} \mid S_{j} \in S, m_{i j}=1, j=1,2, \ldots, n\right\}, \quad i=1,2, \ldots, n$.

Furthermore, an intersection set $C\left(S_{i}\right)$ is defined, i.e., $R\left(S_{i}\right) \cap Q\left(S_{i}\right)$, as follows:

$C\left(S_{i}\right)=\left\{S_{j} \mid S_{j} \in S, m_{i j}=1, m_{j i}=1, j=1,2, \ldots, n\right\}, \quad i=1,2, \ldots, n$.

According to the condition of $R\left(S_{i}\right) \cap Q\left(S_{i}\right)=R\left(S_{i}\right)$, hierarchical extraction is carried out. Each round, one layer of elements is extracted. These elements are separated from other elements, and no iteration is carried out until the level of all elements is determined.

Step 4: draw a directed graph. According to the reachability matrix and the obtained hierarchical relationship, a multilevel hierarchical directed graph is drawn.

Step 5: evaluate and modify. Evaluate the points in the model that are inconsistent with the concept and make necessary corrections.

\section{Building Bayesian Network Model}

\subsection{Building the Initial Model}

4.1.1. Defining Variables and Structures. There are many risk factors caused by urban logistics. Our research mainly focuses on the impact of urban logistics on public security, so we focus on the risk factors that are likely to cause hidden dangers to public security. According to literature review [18, 30, 36], survey of transportation companies and combine the actual cases collected, follows the principle of (1) the main factors, (2) the factors available for most logistics accident data, and (3) the factors that are easy to obtain and identify, human factor $(H)$, transportation tools and facilities factor $(F)$, and goods factor $(G)$ are identified as the direct factors of the accidents, and management factor $(M)$ and weather factor $(W)$ are identified as indirect factors. Generally, the research on logistics risk focuses on four aspects: people, machinery, environment, and management. We refine the indicators of these four aspects and creatively incorporate the factor of goods into the study, considering the possible impact of goods categories and improper storage on public security.

Human factor includes professional skill $\left(H_{1}\right)$, physical condition $\left(\mathrm{H}_{2}\right)$, safety awareness $\left(\mathrm{H}_{3}\right)$, and personnel quality $\left(H_{4}\right)$. Transportation tools and facilities factor includes transport vehicle $\left(F_{1}\right)$, maintenance and inspection $\left(F_{2}\right)$, and facility and instrument $\left(F_{3}\right)$. Goods factor includes goods category $\left(G_{1}\right)$ and storage issues $\left(G_{2}\right)$. Tables 1 and 2 provide detailed description and value set of 11 factors. Direct factors have binary (yes/no, normal/abnormal) value sets, while indirect factors may have more values in the value set.

We have collected 96 urban express logistics accidents for public safety in China from 2016 to 2019 [37-39], and we can determine each value of 11 parameters. Table 3 summarizes the accident data.

For example, example 1 in Table 3 represents an accident that happened in Beijing on June 1, 2017, due to a complaint about the wrong operation of a courier. Survey found that the transport company management problems $(M=1)$, the weather is sunny $(W=0)$, the courier professional skill level is not high $\left(H_{1}=1\right)$, the courier is in normal health $\left(H_{2}=0\right)$, the safety awareness of the courier is normal $\left(H_{3}=0\right)$, the courier's quality is low $\left(H_{4}=1\right)$, normal delivery vehicles $\left(F_{1}=0\right)$, the maintenance and inspection of the vehicle are normal $\left(F_{2}=0\right)$, the equipment and maintain are normal $\left(F_{3}=0\right)$, normal delivery goods $\left(G_{1}=0\right)$, and storage requirements are normal $\left(G_{2}=0\right)$.

4.1.2. ISM Model Construction. In this paper, ISM is first used to construct an initial hierarchical model, and then causal mapping is adopted to improve the initial model and transform the structure into $\mathrm{BN}$ model. The research framework is shown in Figure 1.

Step 1: determine the risk factors and their relationship of urban logistics for public safety. Based on the expert knowledge and accident reports, the relationship between the factors involved in the urban express logistics accidents is determined. Any pair of nodes have a relational value set $\left\{S_{i} \longrightarrow S_{j}, S_{i} \leftarrow S_{j}, S_{i} \uparrow S_{j}, S_{i} \mathrm{O} S_{j}\right\} . S_{i} \longrightarrow S_{j}$ indicates that $S_{i}$ directly leads to $S_{j}, S_{i} \uparrow S_{j}$ indicates the interaction between $S_{i}$ and $S_{j}, S_{i}$ OS $S_{j}$ indicates that the two factors are irrelevant. The details are shown in Table 4.

Step 2: construct the structural self-interaction matrix (SSIM) and calculate the reachability matrix $(M)$. SSIM is constructed by determining the direct relationship between the two factors in Step 1:

\begin{tabular}{|c|c|c|c|c|c|c|c|c|c|c|c|}
\hline & $S_{1}$ & $S_{2}$ & $S_{3}$ & $S_{4}$ & $S_{5}$ & $S_{6}$ & $S_{7}$ & $S_{8}$ & $S_{9}$ & $S_{10}$ & $S_{11}$ \\
\hline$S_{1}$ & - 0 & 1 & 1 & 1 & 1 & 1 & 1 & 1 & 1 & 1 & $1]$ \\
\hline$S_{2}$ & 0 & 0 & 0 & 0 & 0 & 1 & 1 & 1 & 1 & 1 & 1 \\
\hline$S_{3}$ & 0 & 1 & 0 & 1 & 0 & 1 & 1 & 1 & 1 & 1 & 1 \\
\hline$S_{4}$ & 0 & 0 & 0 & 0 & 0 & 1 & 1 & 1 & 1 & 1 & 1 \\
\hline$S_{5}$ & 0 & 0 & 0 & 1 & 0 & 1 & 1 & 1 & 1 & 1 & 1 \\
\hline$A=S_{6}$ & 0 & 0 & 0 & 0 & 0 & 0 & 1 & 1 & 1 & 1 & 1 \\
\hline$S_{7}$ & 0 & 0 & 0 & 0 & 0 & 1 & 0 & 1 & 1 & 1 & 1 \\
\hline$S_{8}$ & 0 & 0 & 0 & 0 & 0 & 1 & 1 & 0 & 1 & 1 & 1 \\
\hline$S_{9}$ & 0 & 0 & 0 & 0 & 0 & 1 & 1 & 1 & 0 & 1 & 1 \\
\hline$S_{10}$ & 0 & 0 & 0 & 0 & 0 & 0 & 0 & 0 & 0 & 0 & 1 \\
\hline$S_{11}$ & 0 & 0 & 0 & 0 & 0 & 0 & 0 & 0 & 0 & 1 & 0 \\
\hline
\end{tabular}


TABLE 1: Direct factors involved in urban express logistics for public safety accidents.

\begin{tabular}{|c|c|c|}
\hline Direct factors & Description & Value set \\
\hline \multicolumn{3}{|l|}{ Human $(H)$} \\
\hline Professional skill $\left(H_{1}\right)$ & Skill, experience & $\begin{array}{l}\text { Normal (0), } \\
\text { Abnormal (1) }\end{array}$ \\
\hline Physical condition $\left(H_{2}\right)$ & Sickness, fatigue & $\begin{array}{l}\text { Normal (0), } \\
\text { Abnormal (1) }\end{array}$ \\
\hline Safety awareness $\left(H_{3}\right)$ & Safety awareness & $\begin{array}{l}\text { Normal (0), } \\
\text { Abnormal (1) }\end{array}$ \\
\hline Personnel quality $\left(H_{4}\right)$ & Quality, follow rules & $\begin{array}{l}\text { Normal (0), } \\
\text { Abnormal (1) }\end{array}$ \\
\hline \multicolumn{3}{|l|}{ Transportation tools and facilities $(F)$} \\
\hline Transport vehicle $\left(F_{1}\right)$ & Transport vehicle meets specified requirements & $\begin{array}{l}\text { Normal (0), } \\
\text { Abnormal (1) }\end{array}$ \\
\hline Maintenance and inspection $\left(F_{2}\right)$ & Transport vehicle is maintained regularly & $\begin{array}{l}\text { Normal (0), } \\
\text { Abnormal (1) }\end{array}$ \\
\hline Facility and instrument $\left(F_{3}\right)$ & Transport vehicle is equipped with the required equipment & $\begin{array}{l}\text { Normal (0), } \\
\text { Abnormal (1) }\end{array}$ \\
\hline \multicolumn{3}{|l|}{ Goods factor $(G)$} \\
\hline Goods category $\left(G_{1}\right)$ & Goods are inflammable, explosive, poisonous, or other contraband & $\begin{array}{l}\text { Normal (0), } \\
\text { Abnormal (1) }\end{array}$ \\
\hline Storage issues $\left(G_{2}\right)$ & Store as required & $\begin{array}{l}\text { Normal (0), } \\
\text { Abnormal (1) }\end{array}$ \\
\hline
\end{tabular}

TABLE 2: Indirect factors involved in urban express logistics for public safety accidents.

\begin{tabular}{lcc}
\hline Indirect factors & Description & Value set \\
\hline Management $(M)$ & Manage personnel, facilities, storage, etc. & Normal (0), \\
Weather $(W)$ & Weather condition & Abnormal (1)
\end{tabular}

By means of 4 steps of Boolean operation, $M$ can be calculated. $N \neq N^{2} \neq N^{3}=N^{4}=M$. Table 5 shows the accessible set, the antecedent set, and their intersection set table, and the structural relationship among the factors is established. The factors of accessible set include the elements of matrix $M$ whose corresponding row value is 1 , including the factors themselves and the factors that may affect. By contrast, the antecedent set consists of the elements of matrix $M$ corresponding to the column median of 1 , including the factors themselves and the factors that may affect them.

Firstly, the hierarchy is extracted according to the condition $R\left(S_{i}\right) \cap Q\left(S_{i}\right)=R\left(S_{i}\right)$. The factors that satisfy the condition are the top layer in the hierarchy. Then the top level factors in the subsequent analysis are removed and the same process is repeated to identify the next level factors. The grading process continues until the level of each factor is found:

$$
M=\left[\begin{array}{lllllllllll}
1 & 1 & 1 & 1 & 1 & 1 & 1 & 1 & 1 & 1 & 1 \\
0 & 1 & 0 & 0 & 0 & 1 & 1 & 1 & 1 & 1 & 1 \\
0 & 1 & 1 & 1 & 0 & 1 & 1 & 1 & 1 & 1 & 1 \\
0 & 0 & 0 & 1 & 0 & 1 & 1 & 1 & 1 & 1 & 1 \\
0 & 0 & 0 & 1 & 1 & 1 & 1 & 1 & 1 & 1 & 1 \\
0 & 0 & 0 & 0 & 0 & 1 & 1 & 1 & 1 & 1 & 1 \\
0 & 0 & 0 & 0 & 0 & 1 & 1 & 1 & 1 & 1 & 1 \\
0 & 0 & 0 & 0 & 0 & 1 & 1 & 1 & 1 & 1 & 1 \\
0 & 0 & 0 & 0 & 0 & 1 & 1 & 1 & 1 & 1 & 1 \\
0 & 0 & 0 & 0 & 0 & 0 & 0 & 0 & 0 & 1 & 1 \\
0 & 0 & 0 & 0 & 0 & 0 & 0 & 0 & 0 & 1 & 1
\end{array}\right] .
$$

Step 3: ISM model divides the risk factors of urban express logistics into different hierarchical structures, and the results are as follows: 
TABLE 3: Parameter values of 96 case studies are used to support the Bayesian network analysis of factors of urban logistics express delivery for public safety accidents.

\begin{tabular}{|c|c|c|c|c|c|c|c|c|c|c|c|}
\hline Sample & $M$ & $W$ & $H_{1}$ & $\mathrm{H}_{2}$ & $\mathrm{H}_{3}$ & $\mathrm{H}_{4}$ & $F_{1}$ & $F_{2}$ & $F_{3}$ & $G_{1}$ & $G_{2}$ \\
\hline 1 & 1 & 0 & 1 & 0 & 0 & 1 & 0 & 0 & 0 & 0 & 0 \\
\hline 2 & 0 & 0 & 0 & 0 & 0 & 1 & 0 & 0 & 0 & 0 & 0 \\
\hline 3 & 1 & 0 & 1 & 0 & 0 & 1 & 0 & 0 & 0 & 0 & 0 \\
\hline 4 & 1 & 0 & 0 & 0 & 0 & 1 & 0 & 0 & 0 & 0 & 0 \\
\hline 5 & 1 & 0 & 1 & 0 & 0 & 1 & 0 & 0 & 0 & 0 & 0 \\
\hline 6 & 1 & 0 & 1 & 0 & 0 & 1 & 0 & 0 & 0 & 0 & 0 \\
\hline 7 & 0 & 0 & 1 & 0 & 1 & 0 & 0 & 0 & 0 & 0 & 0 \\
\hline 8 & 0 & 0 & 1 & 0 & 1 & 0 & 0 & 0 & 0 & 0 & 0 \\
\hline 9 & 0 & 0 & 1 & 0 & 1 & 0 & 0 & 0 & 0 & 0 & 0 \\
\hline 10 & 1 & 0 & 1 & 0 & 1 & 0 & 0 & 0 & 0 & 0 & 0 \\
\hline 11 & 1 & 0 & 0 & 0 & 1 & 0 & 0 & 0 & 0 & 0 & 0 \\
\hline 12 & 1 & 0 & 0 & 0 & 1 & 1 & 0 & 0 & 0 & 0 & 0 \\
\hline 13 & 1 & 0 & 0 & 0 & 1 & 1 & 0 & 0 & 0 & 0 & 0 \\
\hline 14 & 1 & 0 & 0 & 0 & 1 & 1 & 0 & 0 & 0 & 0 & 0 \\
\hline 15 & 1 & 0 & 0 & 0 & 1 & 0 & 0 & 0 & 0 & 1 & 0 \\
\hline 16 & 1 & 0 & 0 & 0 & 0 & 1 & 0 & 0 & 0 & 0 & 0 \\
\hline 17 & 0 & 0 & 1 & 0 & 1 & 0 & 0 & 0 & 0 & 0 & 0 \\
\hline 18 & 1 & 0 & 1 & 0 & 1 & 1 & 0 & 0 & 0 & 0 & 0 \\
\hline 19 & 1 & 0 & 0 & 0 & 0 & 1 & 0 & 0 & 0 & 0 & 0 \\
\hline 20 & 1 & 0 & 0 & 0 & 0 & 1 & 0 & 0 & 0 & 0 & 0 \\
\hline 21 & 1 & 0 & 0 & 0 & 0 & 1 & 0 & 0 & 0 & 0 & 0 \\
\hline 22 & 1 & 0 & 0 & 0 & 0 & 1 & 0 & 0 & 0 & 0 & 0 \\
\hline 23 & 1 & 0 & 1 & 0 & 1 & 0 & 0 & 0 & 0 & 0 & 0 \\
\hline 24 & 0 & 0 & 0 & 1 & 1 & 0 & 0 & 0 & 0 & 0 & 0 \\
\hline 25 & 0 & 0 & 1 & 0 & 0 & 0 & 0 & 0 & 0 & 0 & 0 \\
\hline 26 & 0 & 0 & 1 & 0 & 1 & 0 & 0 & 0 & 0 & 0 & 0 \\
\hline 27 & 1 & 0 & 1 & 0 & 1 & 0 & 0 & 0 & 0 & 0 & 0 \\
\hline 28 & 0 & 2 & 1 & 0 & 0 & 0 & 0 & 0 & 0 & 0 & 0 \\
\hline 29 & 1 & 0 & 1 & 0 & 1 & 0 & 0 & 0 & 0 & 0 & 0 \\
\hline 30 & 1 & 0 & 1 & 0 & 1 & 0 & 1 & 1 & 0 & 0 & 0 \\
\hline 31 & 1 & 0 & 0 & 0 & 1 & 0 & 1 & 1 & 0 & 0 & 0 \\
\hline 32 & 1 & 1 & 0 & 0 & 1 & 0 & 1 & 1 & 0 & 1 & 0 \\
\hline 33 & 0 & 0 & 0 & 1 & 1 & 0 & 0 & 0 & 0 & 0 & 0 \\
\hline 34 & 0 & 0 & 1 & 0 & 1 & 0 & 0 & 0 & 0 & 0 & 0 \\
\hline 35 & 1 & 0 & 0 & 1 & 1 & 0 & 0 & 0 & 0 & 0 & 0 \\
\hline 36 & 0 & 2 & 1 & 0 & 0 & 0 & 0 & 0 & 0 & 0 & 0 \\
\hline 37 & 0 & 0 & 0 & 0 & 0 & 0 & 0 & 0 & 0 & 1 & 0 \\
\hline 38 & 0 & 2 & 0 & 0 & 0 & 0 & 0 & 0 & 0 & 1 & 0 \\
\hline 39 & 0 & 0 & 1 & 0 & 1 & 0 & 0 & 0 & 0 & 0 & 0 \\
\hline 40 & 0 & 0 & 1 & 0 & 0 & 0 & 0 & 0 & 0 & 1 & 0 \\
\hline 41 & 2 & 0 & 0 & 0 & 0 & 0 & 1 & 1 & 0 & 0 & 0 \\
\hline 42 & 0 & 0 & 1 & 0 & 1 & 0 & 0 & 0 & 0 & 0 & 0 \\
\hline 43 & 1 & 0 & 0 & 0 & 1 & 1 & 0 & 0 & 0 & 0 & 0 \\
\hline 44 & 1 & 0 & 1 & 0 & 1 & 0 & 0 & 1 & 0 & 0 & 0 \\
\hline 45 & 1 & 0 & 0 & 0 & 1 & 1 & 1 & 0 & 0 & 0 & 0 \\
\hline 46 & 0 & 0 & 1 & 0 & 1 & 0 & 0 & 0 & 0 & 0 & 0 \\
\hline 47 & 1 & 0 & 1 & 0 & 1 & 0 & 0 & 0 & 0 & 0 & 0 \\
\hline 48 & 1 & 0 & 0 & 0 & 1 & 1 & 0 & 0 & 0 & 1 & 0 \\
\hline 49 & 1 & 0 & 1 & 0 & 1 & 0 & 0 & 1 & 0 & 0 & 0 \\
\hline 50 & 0 & 0 & 1 & 0 & 1 & 0 & 0 & 0 & 0 & 0 & 0 \\
\hline 51 & 1 & 0 & 0 & 0 & 1 & 1 & 0 & 0 & 0 & 0 & 0 \\
\hline 52 & 1 & 0 & 0 & 0 & 1 & 0 & 0 & 0 & 0 & 0 & 0 \\
\hline 53 & 0 & 1 & 1 & 0 & 1 & 0 & 0 & 0 & 0 & 0 & 0 \\
\hline 54 & 1 & 0 & 0 & 0 & 1 & 0 & 0 & 0 & 0 & 0 & 0 \\
\hline 55 & 0 & 0 & 1 & 0 & 1 & 0 & 0 & 0 & 0 & 0 & 0 \\
\hline 56 & 0 & 0 & 1 & 0 & 1 & 0 & 0 & 0 & 0 & 0 & 0 \\
\hline 57 & 0 & 0 & 1 & 0 & 1 & 0 & 0 & 0 & 0 & 0 & 0 \\
\hline 58 & 1 & 0 & 0 & 1 & 1 & 0 & 0 & 0 & 0 & 0 & 0 \\
\hline
\end{tabular}

TABLE 3: Continued.

\begin{tabular}{lccccccccccc}
\hline Sample & $M$ & $W$ & $H_{1}$ & $H_{2}$ & $H_{3}$ & $H_{4}$ & $F_{1}$ & $F_{2}$ & $F_{3}$ & $G_{1}$ & $G_{2}$ \\
\hline 59 & 1 & 0 & 1 & 0 & 1 & 0 & 0 & 0 & 0 & 0 & 0 \\
60 & 1 & 0 & 0 & 0 & 0 & 0 & 1 & 1 & 1 & 0 & 0 \\
61 & 1 & 0 & 0 & 0 & 1 & 0 & 0 & 0 & 0 & 1 & 1 \\
62 & 1 & 0 & 0 & 0 & 1 & 0 & 1 & 1 & 0 & 0 & 0 \\
63 & 1 & 0 & 0 & 0 & 0 & 0 & 0 & 0 & 0 & 1 & 0 \\
64 & 1 & 0 & 0 & 0 & 0 & 0 & 0 & 0 & 0 & 1 & 0 \\
65 & 1 & 0 & 0 & 0 & 0 & 1 & 0 & 0 & 0 & 1 & 0 \\
66 & 1 & 0 & 0 & 0 & 0 & 0 & 0 & 0 & 0 & 1 & 0 \\
67 & 1 & 0 & 0 & 0 & 0 & 0 & 0 & 0 & 0 & 1 & 0 \\
68 & 1 & 0 & 0 & 0 & 0 & 0 & 0 & 0 & 0 & 1 & 0 \\
69 & 1 & 0 & 0 & 0 & 0 & 0 & 0 & 0 & 0 & 1 & 0 \\
70 & 1 & 0 & 0 & 0 & 0 & 0 & 0 & 0 & 0 & 1 & 0 \\
71 & 1 & 0 & 1 & 0 & 0 & 0 & 0 & 0 & 0 & 1 & 0 \\
72 & 1 & 0 & 0 & 0 & 0 & 0 & 0 & 0 & 0 & 1 & 0 \\
73 & 1 & 0 & 0 & 0 & 0 & 0 & 0 & 0 & 0 & 1 & 0 \\
74 & 1 & 0 & 0 & 0 & 0 & 0 & 0 & 0 & 0 & 1 & 0 \\
75 & 1 & 0 & 0 & 0 & 0 & 0 & 0 & 0 & 0 & 1 & 0 \\
76 & 1 & 0 & 0 & 0 & 0 & 0 & 0 & 0 & 0 & 1 & 0 \\
77 & 1 & 0 & 0 & 0 & 0 & 0 & 0 & 0 & 0 & 1 & 0 \\
78 & 1 & 0 & 0 & 0 & 0 & 0 & 0 & 0 & 0 & 1 & 0 \\
79 & 1 & 0 & 0 & 0 & 0 & 0 & 0 & 0 & 0 & 1 & 0 \\
80 & 1 & 0 & 0 & 0 & 0 & 0 & 0 & 0 & 0 & 1 & 0 \\
81 & 1 & 0 & 0 & 0 & 0 & 0 & 0 & 0 & 0 & 1 & 0 \\
82 & 1 & 0 & 0 & 0 & 1 & 0 & 0 & 0 & 0 & 0 & 0 \\
83 & 1 & 0 & 0 & 0 & 1 & 0 & 0 & 0 & 0 & 0 & 0 \\
84 & 1 & 0 & 0 & 0 & 1 & 1 & 0 & 0 & 0 & 0 & 0 \\
85 & 1 & 0 & 0 & 0 & 1 & 0 & 0 & 0 & 0 & 1 & 1 \\
86 & 1 & 1 & 0 & 0 & 1 & 0 & 0 & 0 & 0 & 1 & 1 \\
87 & 1 & 0 & 0 & 0 & 1 & 0 & 0 & 0 & 0 & 1 & 0 \\
88 & 1 & 0 & 0 & 0 & 1 & 0 & 0 & 0 & 0 & 0 & 0 \\
89 & 1 & 0 & 0 & 0 & 1 & 0 & 0 & 0 & 0 & 0 & 0 \\
90 & 1 & 0 & 0 & 0 & 1 & 0 & 0 & 0 & 0 & 0 & 1 \\
91 & 1 & 0 & 0 & 0 & 1 & 0 & 0 & 0 & 1 & 0 & 0 \\
92 & 1 & 0 & 0 & 0 & 1 & 0 & 0 & 0 & 0 & 0 & 0 \\
93 & 1 & 0 & 0 & 0 & 1 & 0 & 0 & 0 & 0 & 0 & 0 \\
94 & 1 & 0 & 0 & 0 & 1 & 1 & 0 & 0 & 0 & 0 & 0 \\
95 & 1 & 0 & 0 & 0 & 1 & 0 & 0 & 0 & 0 & 0 & 0 \\
96 & 1 & 0 & 1 & 0 & 1 & 0 & 0 & 0 & 0 & 0 & 0 \\
\hline & & & & & & & & & & &
\end{tabular}

$$
\begin{aligned}
& L_{1}=\left\{S_{10}, S_{11}\right\}, \\
& L_{2}=\left\{S_{7}, S_{8}, S_{9}\right\}, \\
& L_{3}=\left\{S_{3}, S_{5}\right\}, \\
& L_{4}=\left\{S_{4}, S_{6}\right\}, \\
& L_{5}=\left\{S_{1}, S_{2}\right\} .
\end{aligned}
$$

Table 6 shows the structural hierarchy of risk factors, among which management factor and weather factor are first identified as level 5 . The first level is the goods factor, including the goods category factor and storage issues factor. The main factors including human factor and transportation tools and facilities factor are in the middle level.

Step 4: according to the hierarchical relationship obtained in Step 3, a multilevel hierarchical directed graph is drawn, and the initial model of BN is established, as shown in Figure 2. 


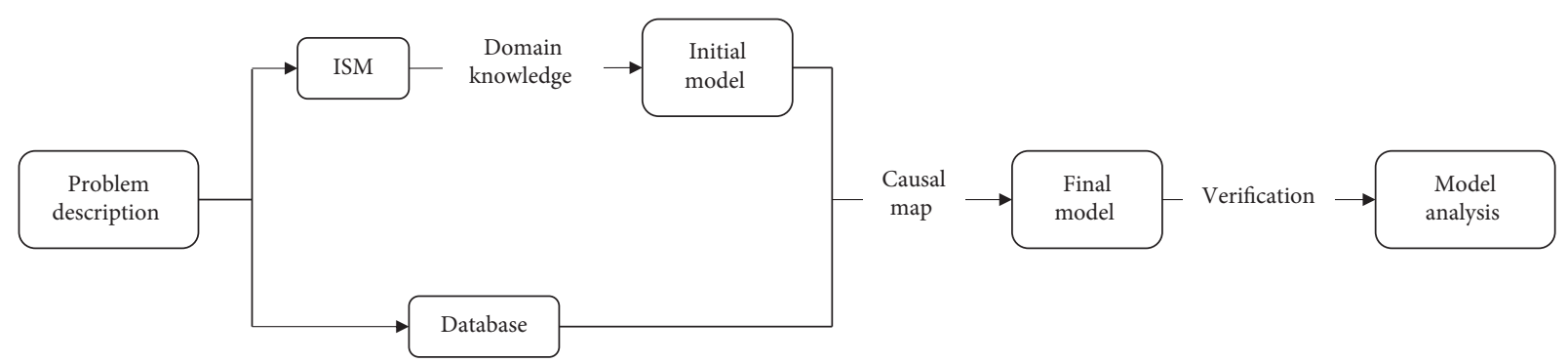

FIGURE 1: The research framework of combining ISM and causal mapping to construct BN.

TABLe 4: Structural self-interaction matrix (SSIM).

\begin{tabular}{|c|c|c|c|c|c|c|c|c|c|c|c|}
\hline & $M$ & $W$ & $H_{1}$ & $\mathrm{H}_{2}$ & $\mathrm{H}_{3}$ & $H_{4}$ & $F_{1}$ & $F_{2}$ & $F_{3}$ & $G_{1}$ & $G_{2}$ \\
\hline$M$ & & 0 & $\longrightarrow$ & $\longrightarrow$ & $\longrightarrow$ & $\longrightarrow$ & $\longrightarrow$ & $\longrightarrow$ & $\longrightarrow$ & $\longrightarrow$ & $\longrightarrow$ \\
\hline$W$ & & & $\longrightarrow$ & 0 & 0 & 0 & 0 & 0 & O & 0 & $\longrightarrow$ \\
\hline$H_{1}$ & & & & 0 & 0 & 0 & $\longrightarrow$ & 0 & 0 & $\longrightarrow$ & $\longrightarrow$ \\
\hline $\mathrm{H}_{2}$ & & & & & $\longrightarrow$ & 0 & $\longrightarrow$ & 0 & O & 0 & 0 \\
\hline $\mathrm{H}_{3}$ & & & & & & $\longleftarrow$ & $\longrightarrow$ & $\longrightarrow$ & 0 & $\longrightarrow$ & $\longrightarrow$ \\
\hline$H_{4}$ & & & & & & & 0 & 0 & 0 & $\longrightarrow$ & 0 \\
\hline$F_{1}$ & & & & & & & & $\uparrow$ & $\uparrow$ & 0 & 0 \\
\hline$F_{2}$ & & & & & & & & & $\longrightarrow$ & 0 & $\longrightarrow$ \\
\hline$F_{3}$ & & & & & & & & & & 0 & $\longrightarrow$ \\
\hline$G_{1}$ & & & & & & & & & & & $\uparrow$ \\
\hline$G_{2}$ & & & & & & & & & & & \\
\hline
\end{tabular}

$\longrightarrow$ : row has an effect on the column; $\longleftarrow$ : column has an effect on the row; $\uparrow$ : row and column interact; $\mathrm{O}$ : the two factors are irrelevant.

TABLE 5: Accessible set and antecedent set and their intersection set table.

\begin{tabular}{lccc}
\hline$I$ & $R\left(S_{i}\right)$ & $Q\left(S_{i}\right)$ & $R\left(S_{i}\right) \cap Q\left(S_{i}\right)$ \\
\hline 1 & $1,3,4,5,6,7,8,9,10,11$ & 1 & 1 \\
2 & $2,3,7,8,9,10,11$ & 2 & 2 \\
3 & $3,7,8,9,10,11$ & $1,2,3,4$ & 3 \\
4 & $3,4,5,7,8,9,10,11$ & 1,4 & 4 \\
5 & $5,7,8,9,10,11$ & $1,5,6$ & 5 \\
6 & $5,6,7,8,9,10,11$ & 1,6 & 6 \\
7 & $7,8,9,10,11$ & $1,2,3,5,6,7,8,9$ & $7,8,9$ \\
8 & $7,8,9,10,11$ & $1,2,3,5,6,7,8,9$ & $7,8,9$ \\
9 & $7,8,9,10,11$ & $1,2,3,5,6,7,8,9$ & $7,8,9$ \\
10 & 10,11 & $1,2,3,5,6,7,8,9,10,11$ & 10,11 \\
11 & 10,11 & $1,2,3,5,6,7,8,9,10,11$ & 10,11 \\
\hline
\end{tabular}

ISM method is used for risk identification, the hierarchical structure is established, and the initial directed graph of $\mathrm{BN}$ is further developed. The network diagram describes the horizontal interdependence among factors and the vertical influence of factors at different levels.

4.2. Improving the Bayesian Network Structure. The initial network diagram is complex and shows circular links that are not allowed in Bayesian network. So we changed the initial network diagram to be $\mathrm{BN}$ compatible. The modification of the initial model is based on a causal mapping method proposed by Nadkarni and Shenoy [40]. When modifying network graph, this method generally adopts two principles. The first principle is to reduce the complexity of the network presentation by removing redundant links. This requires the distinction between direct and indirect relationships, and only direct relationships remain. For example, although management factor $(M)$ is related to safety awareness factor $\left(\mathrm{H}_{3}\right)$, experts believe that the direct relationship between the two factors is weak. $M$ directly affects physical condition $\left(\mathrm{H}_{2}\right)$ and personnel quality $\left(\mathrm{H}_{4}\right)$, both of which subsequently affect $H_{3}$. Therefore, the link to $H_{3}$ was removed from the network.

The second principle is to eliminate any cyclic relationships to satisfy the noncyclic graphic structure of $\mathrm{BN}$. For example, transport vehicle $\left(F_{1}\right)$, maintenance and inspection $\left(F_{2}\right)$, and facility and instrument $\left(F_{3}\right)$ are interrelated, forming a circular connection. $F_{2}$ will affect the performance of the vehicle and then cause latent risks, which is directly related to $F_{1}$. However, when the availability of vehicle is not a problem, $F_{1}$ has no significant influence on $F_{2}$, which is the same with $F_{3}$. Therefore, the relationship between them can be eliminated. Finally, a directed graph suitable for $\mathrm{BN}$ is shown in Figure 3.

The perfect network diagram using causal mapping method specifies the interdependence between the same-level or crosslevel factors, which makes the overall structure clear and easy to understand, deals with the relations among factors more effectively, and ensures a deeper understanding of the problem.

4.3. Parameter Learning of Bayesian Network. When the BN structure is established, the values of some variables can be obtained from the case database, and then the parameters of the model (i.e. conditional probability) can be estimated with these cases. This is called parameter estimation or parameter learning. Maximum likelihood estimation algorithm (MLE) is a universal method to find a set of parameters of maximum likelihood $\theta$, provided that a complete dataset is available. Record the sample set as $D=$ $\left\{x_{1}, x_{2}, \ldots, x_{N}\right\}$.

The joint probability density function $p(D \mid \theta)$ is called the likelihood function of $\theta$ relative to $\left\{x_{1}, x_{2}, \ldots, x_{N}\right\}$ and is defined as follows:

$$
l(\theta)=p(D \mid \theta)=p\left\{x_{1}, x_{2}, \ldots, x_{N} \mid \theta\right\}=\prod_{i=1}^{N} p\left(x_{i} \mid \theta\right) .
$$


TABLE 6: Factor rating table.

\begin{tabular}{lcc}
\hline Level & Factors & Category \\
Level 1 & Goods category $\left(G_{1}\right)$, & Goods factor $(G)$ \\
& Storage issues $\left(G_{2}\right)$ & Transport vehicle $\left(F_{1}\right)$, \\
Layer 2 & Maintenance and inspection $\left(F_{2}\right)$, & Tuman factor $(H)$ \\
& Facility and instrument $\left(F_{3}\right)$ & Human factor $(H)$ \\
Layer 3 & Professional skill $\left(H_{1}\right)$, & Hum tools and facilities $(F)$ \\
Layer 4 & Safety awareness $\left(H_{3}\right)$ & Management $(M)$, weather $(W)$ \\
Layer 5 & Physical condition $\left(H_{2}\right)$, & Personnel quality $\left(H_{4}\right)$ \\
\end{tabular}

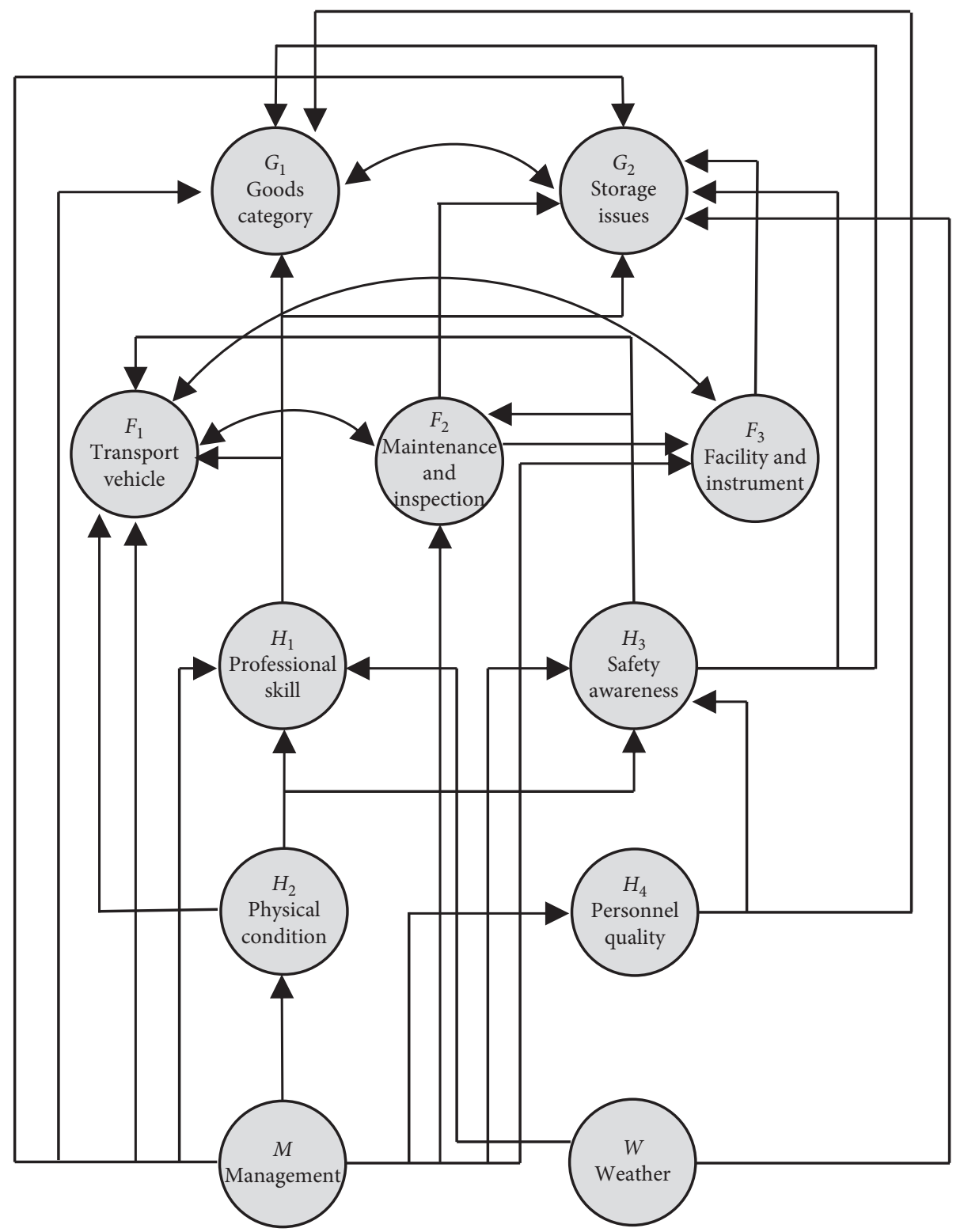

FIgURe 2: Preliminary digraph from ISM. 


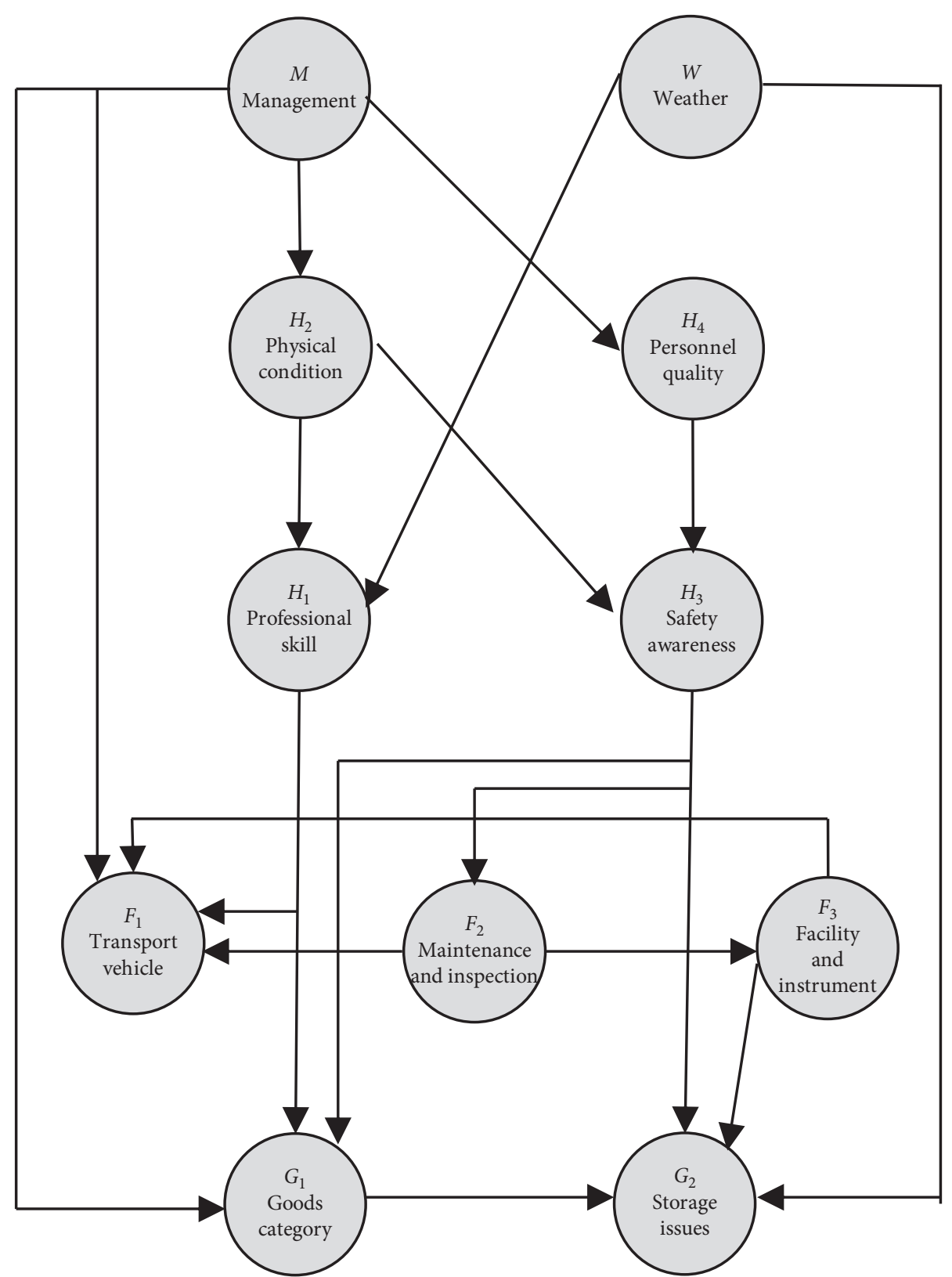

Figure 3: Bayesian network based on ISM digraph.

If $\widehat{\theta}$ is the value $\theta$ can make the likelihood function $l(\theta)$ largest in the parameter space, $\hat{\theta}$ is the maximum likelihood estimator of $\theta$. In order to facilitate analysis, the logarithmic similarity is defined as follows:

$$
\begin{aligned}
\widehat{\theta} & =d\left\{x_{1}, x_{2}, \ldots, x_{N}\right\}=\underset{\theta}{\arg \max } \ln l(\theta) \\
& =\underset{\theta}{\arg \max } \sum_{i=1}^{N} \ln p\left(x_{i} \mid \theta\right) .
\end{aligned}
$$

We use Netica32 software and combined the sample data in Table 3 to complete the parameter learning process. Table 7 shows a CPT example associated with the child factor $\mathrm{H}_{3}$ (safety awareness) and its corresponding parent factors $\mathrm{H}_{2}$ (physical condition) and $H_{4}$ (personnel quality). Figure 4
TABLE 7: An example of a conditional probability table.

\begin{tabular}{lcccc}
\hline & $H_{3}$ & \multicolumn{3}{c}{ Father node } \\
0 & 1 & $M$ & $F_{2}$ \\
\hline 0.375 & 0.625 & 0 & 0 \\
0.166 & 0.833 & 0 & 1 \\
0.541 & 0.458 & 1 & 0 \\
0.5 & 0.5 & 1 & 1 \\
\hline
\end{tabular}

shows the established $\mathrm{BN}$ model. Assume that $F_{2}$ (maintenance and inspection) is taken as the evidence variable and the state value is set to 1 , indicating that the evidence variable is known state. The result is shown in Figure 5.

At this time, the abnormal probability of $F_{1}$ (vehicle state) changes from $12.6 \%$ to $62.1 \%$, the abnormal 


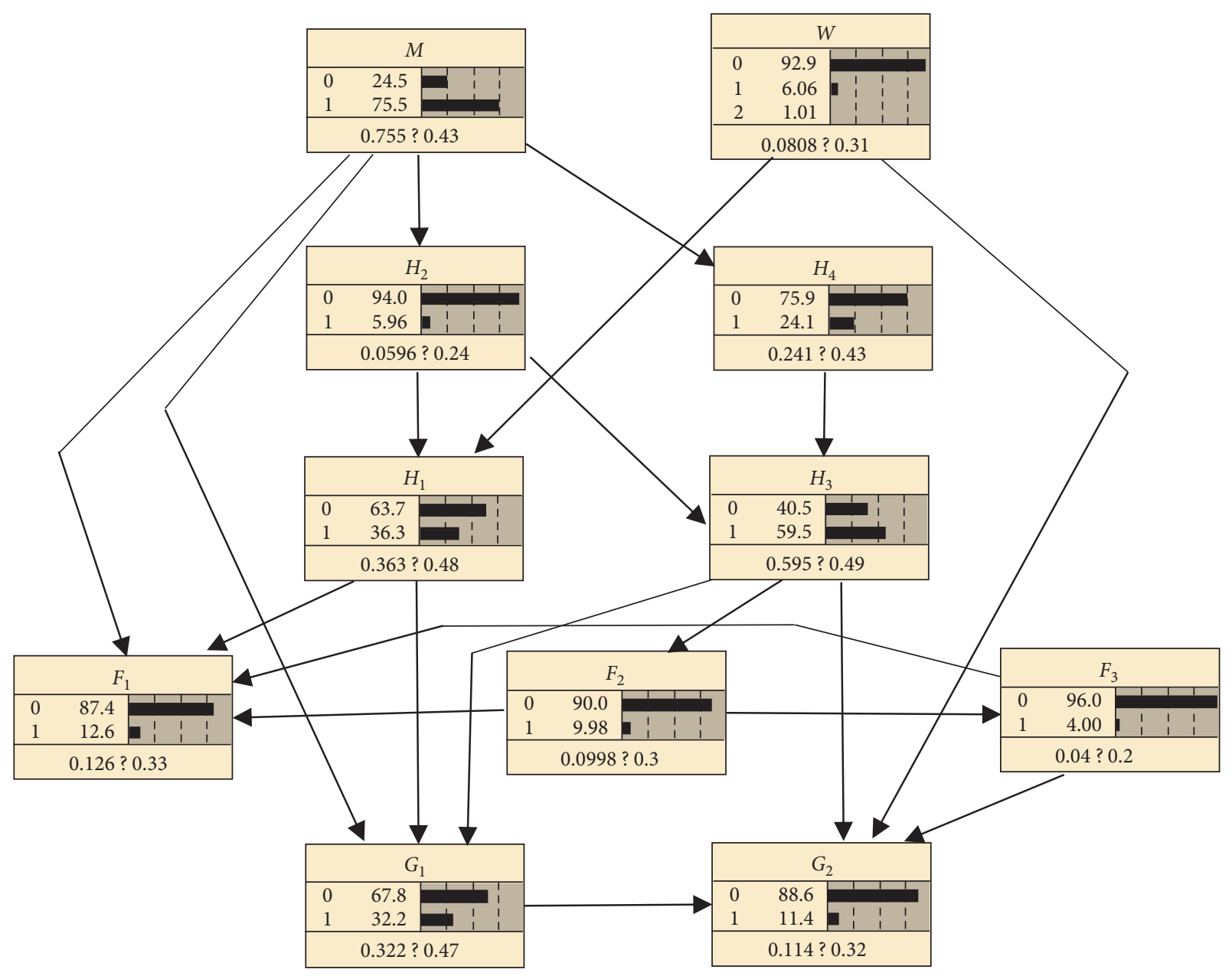

Figure 4: Bayesian network model by Netica.

probability of $F_{3}$ (facilities and instrument) changes from $4.0 \%$ to $20.0 \%$, and the abnormal probability of $G_{2}$ (storage issues) changes from $11.4 \%$ to $16.4 \%$. It can be seen that the risk probability of other factors will increase if the maintenance and supervision work is not done properly.

4.4. Sensitivity Analysis. One of the main functions of $\mathrm{BN}$ is to analyze the evidence sensitivity of query nodes. Sensitivity analysis can get the sensitivity of query node probability to the probability change of evidence node. In probability system, entropy is a common index to express the degree of uncertainty. The following equation represents the entropy of the distribution of the variable $X$ :

$$
H(X)=-\sum_{x \in X} P(x) \log (x) .
$$

Variance is also an indicator of the degree of uncertainty, as shown in the following equation:

$$
\operatorname{Var}(X)=\sum_{x \in X} P(x-\mu)^{2} P(x)
$$

where $\mu$ is the mean, that is, $\sum_{x \in X} x P(x)$.

Table 8 shows the sensitivity analysis of other evidence nodes with $F_{2}$ as an example. Details of other nodes are shown in Table 9. The second column represents the mutual information values, the third column represents the percentage of entropy decreased, and the fourth column is variance.

As can be seen from Table 8, the nodes that have the most influence on $F_{2}$ are their parents and children. The factors that are most likely to have the greatest influence on the reliability of $F_{2}$ are listed in the front.

\section{Discussion}

This paper presents a new risk factor analysis method based on the combination of domain knowledge and data. Nearly 4 years of China's urban logistics express for public safety accident data are modeled, and the sensitivity to risk factors is evaluated. The advantages and development of this study are further discussed as follows:

(1) As a method of probabilistic reasoning, $\mathrm{BN}$ model has some specific advantages over other probabilistic models such as artificial neural network (ANN) and support vector machine (SVM). BN can fuse multiple information sources and infer uncertainty. In the $\mathrm{BN}$ model, domain knowledge can be encoded as a prior distribution, which means that it is independent of any sample data. This feature makes it 


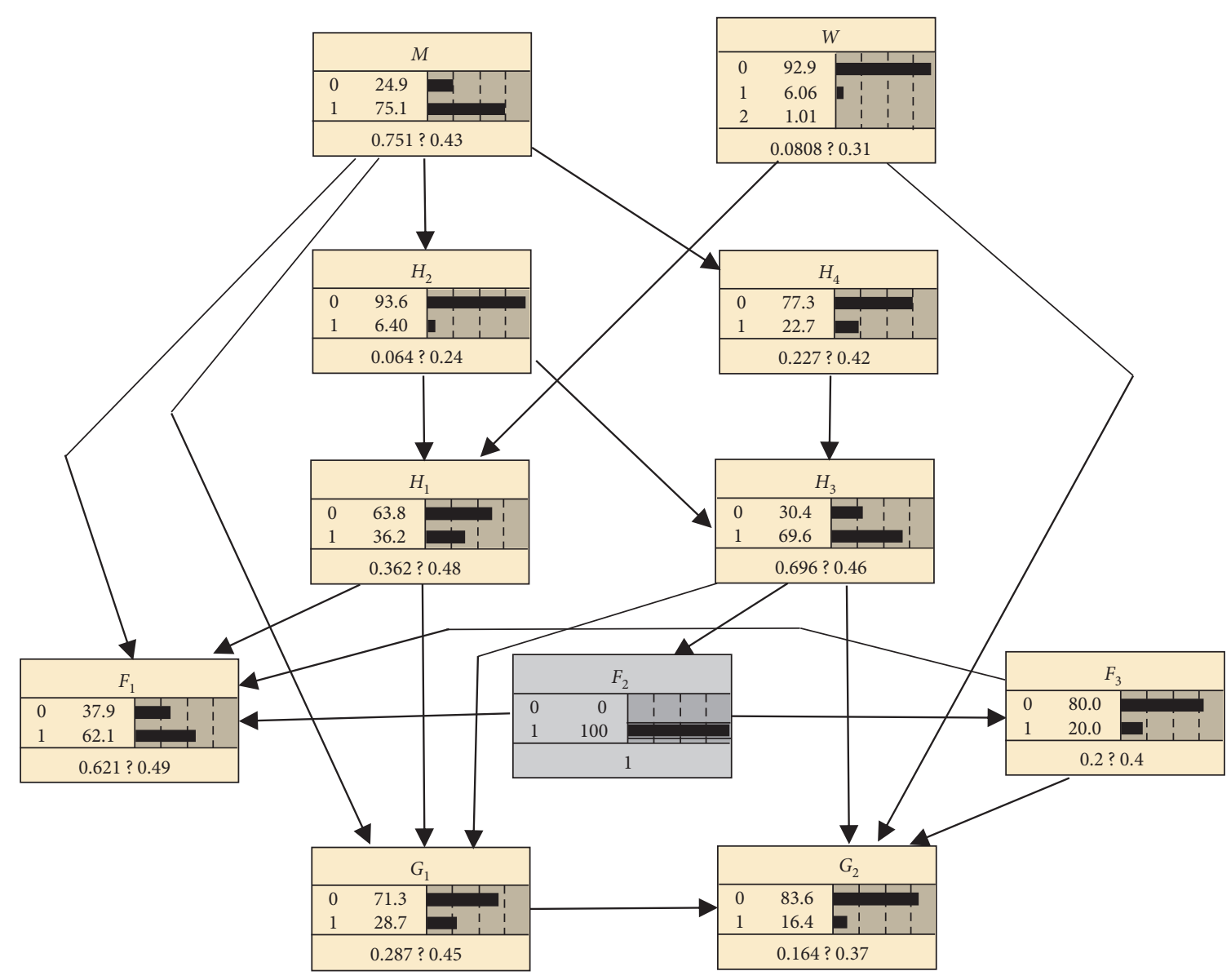

Figure 5: Bayesian network model with perfect $F_{2}$.

TABle 8: Sensitivity of $F_{2}$ to evidence from other nodes.

\begin{tabular}{lccc}
\hline Node & Mutual info & Percent & Variance of beliefs \\
\hline$F_{2}$ & 0.46838 & 100 & 0.0898455 \\
$F_{1}$ & 0.11740 & 25.1 & 0.0220976 \\
$F_{3}$ & 0.03168 & 6.76 & 0.0066493 \\
$H_{3}$ & 0.00346 & 0.74 & 0.0004182 \\
$G_{2}$ & 0.00180 & 0.383 & 0.0002465 \\
$G_{1}$ & 0.00045 & 0.0953 & 0.0000546 \\
$H_{4}$ & 0.00008 & 0.0175 & 0.0000101 \\
$H_{2}$ & 0.00003 & 0.00567 & 0.0000034 \\
$M$ & 0.00001 & 0.00151 & 0.0000009 \\
$H_{1}$ & 0.00000 & 0 & 0.0000000 \\
$W$ & 0.00000 & 0 & 0.0000000 \\
\hline
\end{tabular}

easy to combine domain knowledge with sample data. ANN, on the other hand, usually needs a lot of parameters to learn for a long time and cannot observe its learning process. In addition, $\mathrm{BN}$ can integrate different variable types into a model for processing, such as continuous, discrete, quantitative, and qualitative variables, while ANN and SVM models cannot process. More importantly for BN, the model can be updated according to the new given data. Even incomplete data can be processed to improve the previous $\mathrm{BN}$ model. These are not done by other models such as ANN and SVM.
(2) Comprehensive multisource information for decisionmaking. It is a complex multiattribute decision-making problem to analyze the influencing factors of urban express logistics on public security risk. There are many kinds of information, such as investigation report, detection sensor, and expert opinion. How to integrate objective and subjective data from multiple sources to analyze the risk factors of the system has become an urgent problem. This study combines expert knowledge and accident data and established a comprehensive analysis framework of risk factors of urban express logistics on public safety (Figure 1), including four work links, five risk categories, and 11 influencing factors. According to the results of this study, among all risk factors of urban logistics accident, management error and human factor have the highest prior probability. This result means that most accidents are caused by these factors, which is consistent with previous research results $[18,30]$. It can be considered that management $(M)$ and human factor $(H)$ are the key factors to reduce public safety accidents. Enterprises should further strengthen safety supervision, reduce the employee safety violations, strengthen the safety management of employees, provide safety training courses for employees, strict assessment system, and enhance safety awareness. 
TABle 9: Sensitivity of each node to the others.

\begin{tabular}{|c|c|c|c|}
\hline Node & Mutual & Percent & Variance of beliefs \\
\hline \multicolumn{4}{|c|}{$M$ node } \\
\hline$M$ & 0.80309 & 100 & 0.184923 \\
\hline $\mathrm{H}_{4}$ & 0.03916 & 4.88 & 0.008506 \\
\hline $\mathrm{H}_{2}$ & 0.01323 & 1.65 & 0.003905 \\
\hline$F_{1}$ & 0.00199 & 0.248 & 0.000532 \\
\hline $\mathrm{H}_{3}$ & 0.00154 & 0.192 & 0.000392 \\
\hline$G_{1}$ & 0.00047 & 0.0581 & 0.000119 \\
\hline$H_{1}$ & 0.00012 & 0.0155 & $3.19 E-05$ \\
\hline$G_{2}$ & 0.00001 & 0.0018 & $3.70 E-06$ \\
\hline$F_{2}$ & 0.00001 & 0.000883 & $1.80 E-06$ \\
\hline$F_{3}$ & 0 & $6.46 E-05$ & $1.00 E-07$ \\
\hline$W$ & 0 & 0 & 0 \\
\hline \multicolumn{4}{|c|}{$H_{1}$ node } \\
\hline$H_{1}$ & 0.94504 & 100 & 0.231196 \\
\hline$G_{1}$ & 0.04975 & 5.26 & 0.014953 \\
\hline$W$ & 0.00873 & 0.923 & 0.002924 \\
\hline $\mathrm{H}_{2}$ & 0.00648 & 0.686 & 0.001889 \\
\hline$F_{1}$ & 0.00113 & 0.12 & 0.000356 \\
\hline$G_{2}$ & 0.00039 & 0.0412 & 0.000123 \\
\hline$M$ & 0.00012 & 0.0132 & $3.99 E-05$ \\
\hline $\mathrm{H}_{3}$ & 0.00005 & 0.00503 & $1.53 E-05$ \\
\hline $\mathrm{H}_{4}$ & 0.00001 & 0.00061 & $1.80 E-06$ \\
\hline$F_{2}$ & 0 & $2.22 E-05$ & $1.00 E-07$ \\
\hline$F_{3}$ & 0 & 0 & 0 \\
\hline \multicolumn{4}{|c|}{$W$ node } \\
\hline$W$ & 0.41039 & 100 & 0.068026 \\
\hline$G_{2}$ & 0.02604 & 6.35 & 0.002946 \\
\hline$H_{1}$ & 0.00873 & 2.13 & 0.000799 \\
\hline$G_{1}$ & 0.00061 & 0.149 & $5.25 E-05$ \\
\hline$F_{1}$ & 0.00001 & 0.00353 & $1.30 E-06$ \\
\hline$F_{3}$ & 0 & 0 & 0 \\
\hline$F_{2}$ & 0 & 0 & 0 \\
\hline $\mathrm{H}_{3}$ & 0 & 0 & 0 \\
\hline $\mathrm{H}_{2}$ & 0 & 0 & 0 \\
\hline $\mathrm{H}_{4}$ & 0 & 0 & 0 \\
\hline$M$ & 0 & 0 & 0 \\
\hline \multicolumn{4}{|c|}{$F_{3}$ node } \\
\hline$F_{3}$ & 0.24213 & 100 & 0.038368 \\
\hline$F_{2}$ & 0.03168 & 13.1 & 0.00284 \\
\hline$F_{1}$ & 0.02513 & 10.4 & 0.00202 \\
\hline$G_{2}$ & 0.01578 & 6.52 & 0.001232 \\
\hline $\mathrm{H}_{3}$ & 0.00025 & 0.104 & $1.32 E-05$ \\
\hline$G_{1}$ & 0.00003 & 0.0135 & $1.70 E-06$ \\
\hline$H_{4}$ & 0.00001 & 0.00252 & $3.00 E-07$ \\
\hline $\mathrm{H}_{2}$ & 0 & 0.000824 & $1.00 E-07$ \\
\hline$M$ & 0 & 0.0002 & 0 \\
\hline$H_{1}$ & 0 & 0 & 0 \\
\hline$W$ & 0 & 0 & 0 \\
\hline \multicolumn{4}{|c|}{$\mathrm{H}_{2}$ node } \\
\hline $\mathrm{H}_{2}$ & 0.32582 & 100 & 0.056041 \\
\hline$M$ & 0.01323 & 4.06 & 0.001184 \\
\hline$H_{1}$ & 0.00648 & 1.99 & 0.000458 \\
\hline $\mathrm{H}_{3}$ & 0.00625 & 1.92 & 0.000453 \\
\hline $\mathrm{H}_{4}$ & 0.00074 & 0.227 & $5.44 E-05$ \\
\hline$F_{1}$ & 0.00018 & 0.0541 & $1.43 E-05$ \\
\hline$G_{1}$ & 0.00013 & 0.0403 & $1.01 E-05$ \\
\hline$G_{2}$ & 0.00011 & 0.0332 & $8.70 E-06$ \\
\hline$F_{2}$ & 0.00003 & 0.00817 & $2.10 E-06$ \\
\hline$F_{3}$ & 0 & 0.000608 & $2.00 E-07$ \\
\hline$W$ & 0 & 0 & 0 \\
\hline
\end{tabular}

TABle 9: Continued.

\begin{tabular}{|c|c|c|c|}
\hline Node & Mutual & Percent & Variance of beliefs \\
\hline \multicolumn{4}{|c|}{$G_{1}$ node } \\
\hline$G_{1}$ & 0.90664 & 100 & 0.218347 \\
\hline$H_{3}$ & 0.09421 & 10.4 & 0.028508 \\
\hline$H_{1}$ & 0.04975 & 5.49 & 0.014122 \\
\hline$G_{2}$ & 0.01623 & 1.79 & 0.005234 \\
\hline$H_{4}$ & 0.00247 & 0.272 & 0.00076 \\
\hline$W$ & 0.00061 & 0.0676 & 0.00018 \\
\hline$M$ & 0.00047 & 0.0515 & 0.00014 \\
\hline$F_{2}$ & 0.00045 & 0.0492 & 0.000133 \\
\hline $\mathrm{H}_{2}$ & 0.00013 & 0.0145 & $3.92 E-05$ \\
\hline$F_{3}$ & 0.00003 & 0.00361 & $9.80 E-06$ \\
\hline$F_{1}$ & 0.00003 & 0.0028 & $7.70 E-06$ \\
\hline \multicolumn{4}{|c|}{$\mathrm{H}_{4}$ node } \\
\hline $\mathrm{H}_{4}$ & 0.79685 & 100 & 0.182965 \\
\hline$M$ & 0.03916 & 4.91 & 0.008416 \\
\hline$H_{3}$ & 0.01712 & 2.15 & 0.004403 \\
\hline$G_{1}$ & 0.00247 & 0.31 & 0.000637 \\
\hline $\mathrm{H}_{2}$ & 0.00074 & 0.0927 & 0.000178 \\
\hline$F_{1}$ & 0.0002 & 0.0257 & $5.11 E-05$ \\
\hline$G_{2}$ & 0.0001 & 0.0126 & $2.52 E-05$ \\
\hline$F_{2}$ & 0.00008 & 0.0103 & $2.05 E-05$ \\
\hline$F_{3}$ & 0.00001 & 0.000759 & $1.50 E-06$ \\
\hline$H_{1}$ & 0.00001 & 0.000719 & $1.50 E-06$ \\
\hline$W$ & 0 & 0 & 0 \\
\hline \multicolumn{4}{|c|}{$G_{2}$ node } \\
\hline$G_{2}$ & 0.51192 & 100 & 0.101018 \\
\hline$W$ & 0.02604 & 5.09 & 0.005244 \\
\hline$F_{3}$ & 0.01578 & 3.08 & 0.003244 \\
\hline$G_{1}$ & 0.01623 & 3.17 & 0.002422 \\
\hline $\mathrm{H}_{3}$ & 0.00405 & 0.79 & 0.00055 \\
\hline$F_{2}$ & 0.0018 & 0.351 & 0.000277 \\
\hline$F_{1}$ & 0.00135 & 0.264 & 0.000203 \\
\hline$H_{1}$ & 0.00039 & 0.0761 & $5.39 E-05$ \\
\hline $\mathrm{H}_{2}$ & 0.00011 & 0.0211 & $1.57 E-05$ \\
\hline $\mathrm{H}_{4}$ & 0.0001 & 0.0196 & $1.39 E-05$ \\
\hline$M$ & 0.00001 & 0.00282 & 0.000002 \\
\hline \multicolumn{4}{|c|}{$F_{1}$ node } \\
\hline$F_{1}$ & 0.54699 & 100 & 0.1103 \\
\hline$F_{2}$ & 0.1174 & 24.6 & 0.02713 \\
\hline$F_{3}$ & 0.02513 & 5.27 & 0.005807 \\
\hline$M$ & 0.00199 & 0.288 & 0.000318 \\
\hline$G_{2}$ & 0.00135 & 0.201 & 0.000222 \\
\hline$H_{1}$ & 0.00113 & 0.154 & 0.00017 \\
\hline $\mathrm{H}_{3}$ & 0.00099 & 0.136 & 0.00015 \\
\hline $\mathrm{H}_{4}$ & 0.0002 & 0.0279 & $3.08 E-05$ \\
\hline $\mathrm{H}_{2}$ & 0.00018 & 0.0255 & $2.81 E-05$ \\
\hline$G_{1}$ & 0.00003 & 0.00351 & $3.87 E-06$ \\
\hline$W$ & 0.00001 & 0.00199 & $2.20 E-06$ \\
\hline
\end{tabular}

(3) The output of sensitivity analysis shows that the low safety awareness of employees $\left(\mathrm{H}_{3}\right)$ and management factor $(M)$ are the main reasons of accidents caused by the failure of transportation vehicles. This is consistent with previous research results [41, 42]. Accidents may occur when employees neglect the safety inspection of vehicles and fail to do regular maintenance of vehicles, and the enterprise is poorly supervised. A lack of safety knowledge may be one reason why employees ignore safety issues. In order to reduce these errors, 
the company's management must pay attention to these factors, strengthen supervision, clarify safety management policies, implement safety training plan, improve the staff's attention to details, and reduce mistakes.

(4) Although this study proposes a modeling framework using the artificial intelligence methods, the BN model developed is only a prototype, and further studies are needed to improve it. For example, some of the risk factors identified in urban express logistics represent general operational process concepts. In order to be more realistic, some factors must be refined to manage specific express logistics risk factors. In addition, in order to improve the integrity of BN model, more domain experts should be introduced.

\section{Conclusion}

In this paper, by combining Interpretative Structural Model and causal mapping method, Bayesian network is constructed to analyze the risk factors of urban express logistics on public security, including risk factor identification, relationship analysis between factors, prior probability and likelihood calculation, reasoning, and interpretation. With the help of domain experts, ISM and causal mapping methods can be effectively applied to the BN construction of urban express logistics, extending the application of $\mathrm{BN}$ model in the risk factor analysis of urban logistics. The flexibility of this approach allows the integration of multiple types of information sources to quantify the relationship between risk factors, and the model can be constantly updated based on new information. This study considers more important factors (11 factors) of urban logistics accidents from five aspects of management, weather, human, transportation means, and goods and concludes the interrelation and relative importance of risk factors, revealing that human factor and management factor are important direct factors of accidents. Through the sensitivity analysis, it is concluded that the low safety awareness of employees and the poor management of enterprises bring potential risks to vehicles, so as to increase the possibility of accidents. These research results combined with the actual situation of urban logistics in China have certain practical significance and provide guidance for logistics managers to take necessary measures to reduce accidents.

\section{Data Availability}

The data used to support the results of this study are provided in Table 3.

\section{Conflicts of Interest}

The authors declare that they have no conflicts of interest.

\section{Acknowledgments}

The research was supported by grants from the National Key R\&D Program of China (2018YFB1601600).

\section{References}

[1] E. Taniguchi, R. G. Thompson, T. Yamada, and R. V. Duin, City Logistics: Network Modelling and Intelligent Transport Systems, Elsevier, Amsterdam, The Netherlands, 2001.

[2] C. J. Cao, C. D. Li, Y. Wang, W. B. Li, and F. S. Zhang, "Governance mode of urban public safety risk in big data era," Urban Development Studies, vol. 24, no. 11, pp. 76-82, 2017.

[3] C. Zheng, C. Jin, X. Zhang, W. Meng, and B. Zhang, "Research of items safe hidden trouble in express transportation process," Popular Science and Technology, vol. 14, no. 12, pp. 163-177, 2012.

[4] L. Xuan, D. Y. Wei, and Y. Shi, "A brief analysis of security risks in transportation of logistics enterprises," Chinese Market, vol. 41, p. 68, 2015.

[5] S. Ren, "Assessment on logistics warehouse fire risk based on analytic hierarchy process," Procedia Engineering, vol. 45, pp. 59-63, 2012.

[6] Q. Su and Y. Zhao, "Study on control of logistics risk from the angle of risk management," Logistics Sci-Tech, vol. 30, no. 9, pp. 115-117, 2007.

[7] X. Liu and Z.-y. Tian, "Risk assessment of logistics outsourcing based on BP neural network," in Proceedings of the International Conference on Photonics and Image in Agriculture Engineering, vol. 8762, Article ID 87620D, Sanya, China, March 2013.

[8] T. Song, L. Y. Wei, C. L. Zhang, and P. Chen, "Project logistics risk evaluation based on matter-element analysis," Applied Mechanics and Materials, vol. 174-177, no. 177, pp. 28202824, 2012.

[9] S. Raut and S. Karmore, "Review on: severity estimation unit of automotive accident," in Proceedings of the Computer Engineering and Applications, Ghaziabad, India, March 2015.

[10] H. Alyami, Z. Yang, R. Riahi, S. Bonsall, and J. Wang, "Advanced uncertainty modelling for container port risk analysis," Accident Analysis \& Prevention, vol. 123, pp. 411-421, 2019.

[11] M. Onder, S. Onder, and E. Adiguzel, "Applying hierarchical loglinear models to nonfatal underground coal mine accidents for safety management," International Journal of Occupational Safety and Ergonomics, vol. 20, no. 2, pp. 239-248, 2014.

[12] H. Xiao, X. Cheng, and C. Zou, "The risk analysis and evaluation of urban underground logistics system development based on the grey analytic hierarchy process," The Open Mechanical Engineering Journal, vol. 8, no. 1, pp. 354-357, 2014.

[13] L. Zhao, X. Wang, and Y. Qian, "Analysis of factors that influence hazardous material transportation accidents based on Bayesian networks: a case study in China," Safety Science, vol. 50, no. 4, pp. 1049-1055, 2012.

[14] M. Spada, P. Burgherr, and M. Hohl, “Toward the validation of a National Risk Assessment against historical observations using a Bayesian approach: application to the Swiss case," Journal of Risk Research, vol. 22, no. 11, pp. 1323-1342, 2018.

[15] S.-S. Leu and C.-M. Chang, "Bayesian-network-based safety risk assessment for steel construction projects," Accident Analysis \& Prevention, vol. 54, pp. 122-133, 2013.

[16] N. Batarlienè, "Risk analysis and assessment for transportation of dangerous freight," Transport, vol. 23, no. 2, pp. 98-103, 2008.

[17] D. A. Wiegmann and S. A. Shappell, "Human error analysis of commercial aviation accidents using the human factors analysis and classification system (HFACS)," Aviation Space and Environmental Medicine, vol. 72, no. 11, pp. 1006-1016, 2001. 
[18] C.-d. Chen and Y. Liu, "Analysis on formation reasons and hidden dangers of safety accidents in logistics enterprises' road transport," Journal of Minjiang University, vol. 34, no. 6, pp. 53-58, 2013.

[19] A. Kibe, W. Mwangi, and S. Kimani, "Risk management in financial information systems using Bayesian networks," Journal of Information Engineering and Applications, vol. 4, no. 3, pp. 42-51, 2014.

[20] C. Contaldi, F. Vafaee, and P. C. Nelson, "Bayesian network hybrid learning using an elite-guided genetic algorithm," Artificial Intelligence Review, vol. 52, no. 1, pp. 245-272, 2019.

[21] X. Xie, Y. Liu, V. Perkovic et al., "Renin-angiotensin system inhibitors and kidney and cardiovascular outcomes in patients with ckd: a Bayesian network meta-analysis of randomized clinical trials," American Journal of Kidney Diseases, vol. 67, no. 5, pp. 728-741, 2016.

[22] J. Mi, Y. F. Li, W. Peng, and H. Z. Huang, "Reliability analysis of complex multi-state system with common cause failure based on DS evidence theory and Bayesian network," in Reliability Engineering and System Safety, vol. 174, pp. 71-81, Springer, Berlin, Germany, 2018.

[23] J. Zhou, X. Zhou, X. Du, and F. Wang, "Research on design of dam-break risks control for cascade reservoirs," Journal of Hydroelectric Engineering, vol. 37, no. 1, pp. 1-10, 2018.

[24] C. Liang and M. Ghazel, "A risk assessment study on accidents at French level crossings using Bayesian belief networks," International Journal of Injury Control and Safety Promotion, vol. 25, no. 2, pp. 162-172, 2018.

[25] S. Li, T. Tryfonas, R. Gordon, and A. Panagiotis, "Risk assessment for mobile systems through a multilayered hierarchical Bayesian network," IEEE Transactions on Cybernetics, vol. 46, no. 8, pp. 1749-1759, 2016.

[26] M. M. Aliabadi, H. Aghaei, O. Kalatpour, A. R. Soltanian, and A. Nikravesh, "Analysis of human and organizational factors that influence mining accidents based on Bayesian network," International Journal of Occupational Safety and Ergonomics, Article ID 101080, 2018.

[27] C. Cai and Y. Q. Liu, "Reliability analysis of logistics service supply chain system based on fuzzy Bayesian networks," China Business and Market, vol. 32, no. 4, pp. 49-58, 2018.

[28] Y. Yan and B. Suo, "Risks analysis of logistics financial business based on evidential Bayesian network," Mathematical Problems in Engineering, vol. 2013, Article ID 785218, 8 pages, 2013.

[29] L. S. Zhu and F. Yang, "Bayesian model for agricultural product logistics safety early warning," Revista de la Facultad de Agronomia de la Universidad del Zulia, vol. 36, no. 2, pp. 341-347, 2019.

[30] K. Li, Z.-S. Tan, and X.-Y. Tang, "Research on risk prediction and control of emergency logistics based on Bayesian network," Logistics Sci-Tech, vol. 40, no. 2, pp. 98-101, 2017.

[31] Y. Huang and Q. B. Qian, "Analysis and countermeasures of cold chain transportation failures based on Bayesian network,” Logistics Technology, vol. 37, no. 9, pp. 20-26, 2018.

[32] J.-L. Hu, X.-W. Tang, and J.-N. Qiu, "A Bayesian network approach for predicting seismic liquefaction based on interpretive structural modeling," Georisk: Assessment and Management of Risk for Engineered Systems and Geohazards, vol. 9, no. 3, pp. 200-217, 2015.

[33] J. N. Warfield, "On arranging elements of a hierarchy in graphic form," IEEE Transactions on Systems Man and Cybernetics, vol. SMC-3, no. 2, pp. 121-132, 1973.

[34] M. D. Singh, R. Shankar, R. Narain, and A. Agarwal, "An interpretive structural modeling of knowledge management in engineering industries," Journal of Advances in Management Research, vol. 1, no. 1, pp. 28-40, 2003.

[35] V. Ravi and R. Shankar, "Analysis of interactions among the barriers of reverse logistics," Technological Forecasting and Social Change, vol. 72, no. 8, pp. 1011-1029, 2005.

[36] M. Q. Zhang and Y. Zhou, "Study on the alarming and prevention of logistics operation risk," Logistics Technology, vol. 27, no. 4, pp. 49-51, 2008.

[37] http://www.safehoo.com/.

[38] http://www.esafety.cn/shiguanli/.

[39] http://www.anquan.com.cn/.

[40] S. Nadkarni and P. P. Shenoy, "A causal mapping approach to constructing Bayesian networks," Decision Support Systems, vol. 38, no. 2, pp. 259-281, 2004.

[41] Z. G. Zhu, "Strengthen safety management in logistics and transportation," Traffic Transportation, vol. 1, no. 57, p. 53, 2012.

[42] K. Yang, "Discuss about how to make logistics express transport vehicler traffic safety management," Management Observer, vol. 607, no. 8, pp. 40-41, 2016. 